\title{
Efficacy of Once Daily versus Divided Daily Administration of Low Daily Dosage (15 mg/Day) of Methimazole in the Induction of Euthyroidism in Graves' Hyperthyroidism: A Randomized Controlled Study
}

\author{
Sutin Sriussadaporn, Wanwaroon Pumchumpol, Raweewan Lertwattanarak, \\ and Tada Kunavisarut \\ Division of Endocrinology and Metabolism, Department of Medicine, Faculty of Medicine Siriraj Hospital, Mahidol University, \\ Bangkok, Thailand \\ Correspondence should be addressed to Sutin Sriussadaporn; sutin.sri@mahidol.ac.th
}

Received 12 April 2017; Revised 25 September 2017; Accepted 12 October 2017; Published 18 December 2017

Academic Editor: Henrik Falhammar

Copyright (C) 2017 Sutin Sriussadaporn et al. This is an open access article distributed under the Creative Commons Attribution License, which permits unrestricted use, distribution, and reproduction in any medium, provided the original work is properly cited.

\begin{abstract}
Background. Previous studies used unequal or high daily dosages of methimazole (MMI) to compare the efficacy of once daily dose regimen (OD-MMI) with that of divided daily doses regimen (DD-MMI) in inducing euthyroidism. Objectives. To compare the efficacy of OD-MMI to that of DD-MMI using low daily dosage of MMI in inducing euthyroidism. Methods. Fifty patients with clinically nonsevere Graves' hyperthyroidism were randomized to be treated with $15 \mathrm{mg} / \mathrm{day}$ OD-MMI or $15 \mathrm{mg}$ /day DD-MMI. Results. 21 cases (84\%) in OD-MMI and 23 cases (92\%) in DD-MMI were eligible for analyses. During the treatment, there was no difference in baseline characteristics, serum FT3 and FT4 reductions, and cumulative rate of achieving euthyroidism $(4.8 \%$ versus $4.3 \%, 28.6 \%$ versus $34.8 \%, 71.4 \%$ versus $82.6 \%$, and $85.7 \%$ versus $87.0 \%$ at $2,4,8$, and 12 weeks, resp.) between both regimens. Hypothyroidism developed in DD-MMI significantly more than in OD-MMI (17.4\% versus $0 \%, p<0.05)$. Conclusions. Treatment with MMI at a low daily dosage of $15 \mathrm{mg} /$ day OD-MMI is as effective as DD-MMI in the reduction of serum thyroid hormone levels and induction of euthyroidism. The OD-MMI regimen is preferable to the DD-MMI regimen in the treatment of clinically nonsevere Graves' hyperthyroidism. This trial is registered with Thai Clinical Trials Registry: TCTR20170529001.
\end{abstract}

\section{Introduction}

The American Thyroid Association (ATA)/American Association of Clinical Endocrinologists (AACE) 2011 and The ATA 2016 guidelines recommended methimazole (MMI) for the first line antithyroid drug in the treatment of Graves' hyperthyroidism in nonpregnant patients $[1,2]$. MMI is recommended to be administered either conventionally in two to three divided doses a day, the so-called divided daily doses regimen (DD-MMI), or more preferably once a day, the socalled once daily dose regimen (OD-MMI) [1-4]. However, it is not clearly stated whether OD-MMI and DD-MMI regimens are equally effective in the induction of euthyroidism [1-4]. In addition, the evidences suggesting the equal effectiveness of both regimens were based on only few studies that used unequal $[5,6]$ or high [7] daily dosages of MMI in the comparison between OD-MMI and DD-MMI regimens. Low daily dosages of MMI such as $10-20 \mathrm{mg} /$ day rather than high daily dosages such as $30 \mathrm{mg} /$ day or more are currently recommended in the initial treatment of hyperthyroidism [1-4]. The present randomized controlled study was therefore conducted to compare the efficacy in the 
reduction of serum thyroid hormone levels and induction of euthyroidism between OD-MMI and DD-MMI regimens using an equal dosage of $15 \mathrm{mg} /$ day of MMI in patients with Graves' hyperthyroidism.

\section{Patients and Methods}

Fifty patients with newly diagnosed clinically nonsevere Graves' hyperthyroidism who had never been treated with an antithyroid drug were studied. Graves' hyperthyroidism was diagnosed according to the ATA/AACE 2011 and ATA 2016 guidelines $[1,2]$. In 32 patients, the diagnosis of Graves' hyperthyroidism was based on the presence of symptoms and signs of thyrotoxicosis, elevated serum-free thyroid hormones with suppressed serum thyroid-stimulating hormone (TSH) levels, and one or more specific clinical features including diffuse goiter with audible bruit, ophthalmopathy, and dermopathy. In 18 patients who had none of these specific features, Graves' hyperthyroidism was diagnosed by the presence of either positive anti-TSH receptor antibody (TRAb) (13 cases) or a high percentage (>40\%) of 24 -hourradioactive iodine uptake with a homogeneous pattern of thyroid scintigraphy (5 cases). Clinically nonsevere Graves' hyperthyroidism was defined by the absence of symptoms and signs of severe thyrotoxicosis including heart rate of more than 120 beats/minute, cardiac arrhythmia, congestive heart failure, impaired mental status, jaundice, and markedly elevated serum hepatic enzyme levels of more than 3 times of the upper normal limits. Patients who had the following conditions were excluded: single or multiple palpable thyroid nodules, toxic adenoma, toxic multinodular goiter, painful goiter, pregnancy, lactation, receiving medications known to interfere with thyroid hormone metabolism, and symptoms and signs of severe thyrotoxicosis. The size of thyroid gland was assessed clinically by summation of the volume of each lobe [length $(\mathrm{cm}) \times$ width $(\mathrm{cm}) \times$ depth $(\mathrm{cm})]$ to estimate the weight (expressed in grams) of the thyroid gland as previously described [8].

The patients were randomly allocated to two groups by using a computer-generated block of 4 randomization method. One group was treated with $15 \mathrm{mg} /$ day of MMI which was administered once a day ( $15 \mathrm{mg} /$ day OD-MMI) and the other group was treated with $15 \mathrm{mg} /$ day of MMI which was dividedly administered in $5 \mathrm{mg}$ three times a day (15 mg/day DD-MMI). The therapeutic efficacy was assessed by comparing results of thyroid function tests before and at 2 , 4,8 , and 12 weeks of the study. The dosage of MMI was maintained at $15 \mathrm{mg} /$ day throughout the study and was decreased if hypothyroidism was developed. Euthyroidism was defined by the presence of serum $\mathrm{FT}_{3}$ and $\mathrm{FT}_{4}$ levels within the normal range. Hypothyroidism was defined by the presence of a low serum FT4 level of less than the lower normal limit. At each visit, the patients were assessed for drug compliance by patient interview and pill counting and were intensively instructed to take the prescribed MMI completely. Patients who failed to take more than $90 \%$ of the prescribed MMI pills were defined as nondrug compliant and were excluded. Patients lost to follow-up were interviewed by phone for the reasons for inability to comply with the study protocol. Adverse effects of MMI such as skin rash, fever, sore throat, jaundice, and other symptoms were assessed by patient interview, physical examination, and laboratory tests if indicated at each visit. All subjects agreed to participate in this study and gave informed consent. This study was approved by Siriraj Institutional Review Board (Thai Clinical Trials Registry number: TCTR20170529001).

2.1. Biochemical Analyses. Serum free T4 (FT4) and TSH levels were measured by electrochemiluminescent immunoassay (CLIA) method using an automated machine (Modular E170, USA). Serum free T3 (FT3) was measured by CLIA method using an automated machine (Elecsys, USA). All hormonal measurements were performed in a laboratory that was accredited by the International Organization for Standardization (ISO 15189). The normal ranges were 3.0$7.0 \mathrm{pmol} / \mathrm{L}$ for serum FT3, 12.0-25.0 pmol/L for serum FT4, and $0.23-4.00 \mathrm{mIU} / \mathrm{L}$ for serum TSH levels. TRAb was measured by fast enzyme-linked immunosorbent assay using porcine TSH receptor as an antigen (Euroimmun, Germany) with a positive cutoff level of $>1$ IU/L.

2.2. Statistical Analyses. Results are expressed as percent or mean \pm SD as appropriate. Data obtained from the two treatment regimens were compared and analyzed statistically using a chi-square test for categorical data and Student's $t$ test for continuous data. A $p$ value of $<0.05$ was considered statistically significant.

\section{Results}

There were 50 patients with newly diagnosed Graves' hyperthyroidism recruited in the study. After randomization, 25 cases were treated with $15 \mathrm{mg} /$ day OD-MMI regimen and 25 cases with $15 \mathrm{mg} /$ day DD-MMI regimen. In the ODMMI group, 1 case loss to follow-up at 2 weeks, 2 cases loss to follow-up at 4 weeks of the study due to inability to comply with the follow-up schedule, and 1 case had poor drug compliance that MMI was taken only $76 \%$ of the prescribed pills between the third and fourth weeks of the study. In the DDMMI group, 2 cases had poor drug compliance that MMI was taken only $76 \%$ of the prescribed pills between the third and fourth weeks in one case and $72 \%$ of the prescribed pills between the fifth and eighth weeks in another case. Therefore, 21 cases (84\%) in the OD-MMI group and 23 cases (92\%) in the DD-MMI group were able to complete the 12 week study and were eligible for analyses.

At baseline, there was no significant difference in age, sex, duration of symptoms, goiter size, and serum FT3, FT4, and TSH levels between OD-MMI and DD-MMI groups as shown in Table 1. Both OD-MMI and DD-MMI regimens induced significant reduction in serum FT3 and FT4 levels and induced euthyroidism during the treatment in similar fashions as shown in Figure 1 and Table 2. There was no significant difference between OD-MMI and DD-MMI groups at all visits in serum FT3 levels $(29.24 \pm 14.12$ versus $23.96 \pm 13.74 \mathrm{pmol} / \mathrm{L}$ at 0 week, $11.07 \pm 3.30$ versus $11.60 \pm 4.73 \mathrm{pmol} / \mathrm{L}$ at 2 weeks, $8.61 \pm 3.14$ versus $8.24 \pm 3.43 \mathrm{pmol} / \mathrm{L}$ at 4 weeks, $5.71 \pm 2.08$ versus $6.16 \pm 4.11 \mathrm{pmol} / \mathrm{L}$ at 8 weeks, and $5.53 \pm 2.11$ versus 
TABLE 1: Baseline characteristics of hyperthyroid patients treated with $15 \mathrm{mg} /$ day OD-MMI and $15 \mathrm{mg} / \mathrm{day}$ DD-MMI.

\begin{tabular}{lccc}
\hline & $15 \mathrm{mg} /$ day OD-MMI & $15 \mathrm{mg} /$ day DD-MMI & \\
\hline Total number of patients (cases) & 21 & 23 & $20 / 3$ \\
Sex: females/males (cases) & $13 / 8$ & $41.74 \pm 13.52$ & 0.083 \\
Age (years) & $36.67 \pm 12.53$ & $3.43 \pm 2.50$ & 0.205 \\
Duration of symptoms (months) & $4.11 \pm 3.84$ & $55.28 \pm 10.71$ & 0.914 \\
Body weight (kg) & $58.31 \pm 9.55$ & $1.70 \pm 1.80$ & 0.329 \\
Weight loss (kg/month) & $2.41 \pm 4.35$ & $23.04 \pm 12.13$ & 0.492 \\
Goiter size (g) & $25.95 \pm 18.14$ & $23.96 \pm 13.74$ & 0.532 \\
Serum FT3 (pmol/L) & $29.24 \pm 14.12$ & $56.76 \pm 23.94$ & 0.216 \\
Serum FT4 (pmol/L) & $68.47 \pm 27.80$ & $0.0083 \pm 0.0039$ & 0.141 \\
Serum TSH (mIU/L) & $0.0074 \pm 0.0026$ & $33.56 \pm 23.97$ & 0.401 \\
Serum ALT (IU/dL) & $31.24 \pm 14.61$ & $29.30 \pm 15.02$ \\
Serum AST (IU/dL) & $27.14 \pm 7.38$ & 0.703 \\
\hline
\end{tabular}

Data are demonstrated as mean \pm standard deviation. $15 \mathrm{mg} /$ day OD-MMI, $15 \mathrm{mg}$ /day of methimazole administered once daily; $15 \mathrm{mg} /$ day DD-MMI, $15 \mathrm{mg} /$ day of methimazole administered dividedly in $5 \mathrm{mg}$ three times a day.

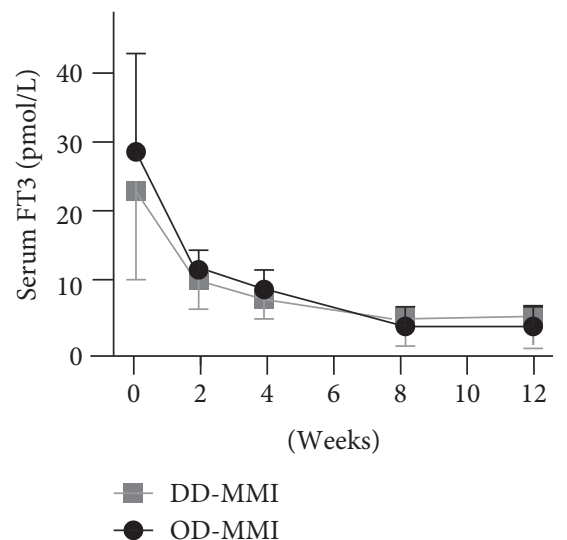

(a)

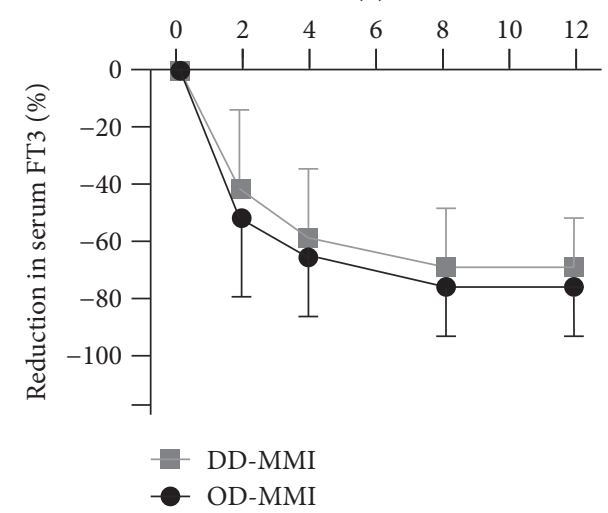

(c)

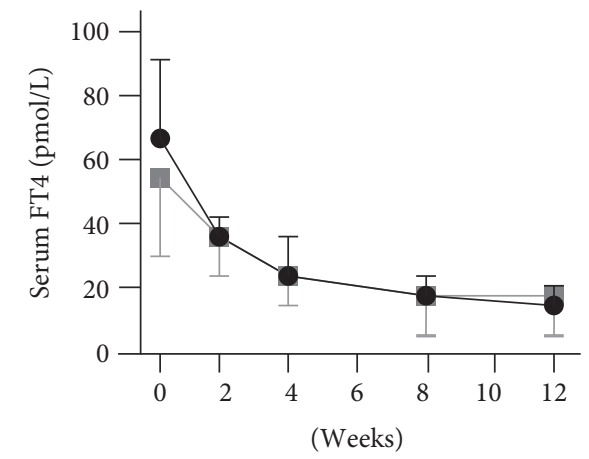

DD-MMI

OD-MMI

(b)

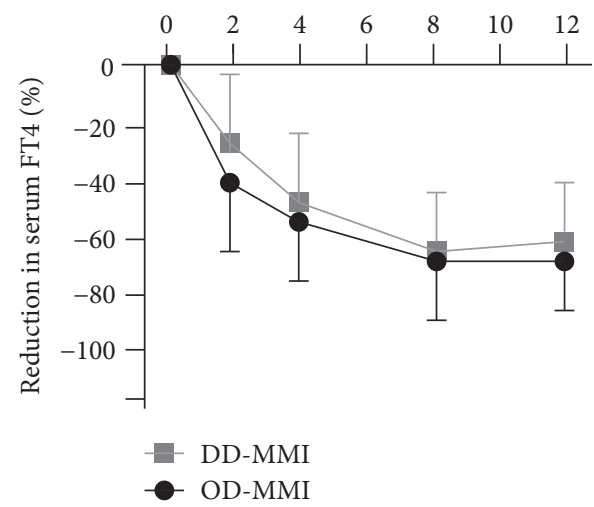

(d)

FIgURE 1: Changes in serum FT3 and FT4 during treatment with $15 \mathrm{mg} /$ day OD-MMI and $15 \mathrm{mg} /$ day DD-MMI. There was no significant difference in serum FT3 (a) and serum FT4 (b) levels and magnitude of reduction in serum FT3 (c) and FT4 (d) levels at all visits during the 12-week treatment with OD-MMI and DD-MMI regimens.

$6.59 \pm 5.21 \mathrm{pmol} / \mathrm{L}$ at 12 weeks $)$ and serum FT4 levels $(68.47 \pm$ 27.80 versus $56.76 \pm 23.94 \mathrm{pmol} / \mathrm{L}$ at 0 week, $34.62 \pm 10.68$ versus $35.14 \pm 11.07 \mathrm{pmol} / \mathrm{L}$ at 2 weeks, $26.64 \pm 10.17$ versus $26.39 \pm 10.55 \mathrm{pmol} / \mathrm{L}$ at 4 weeks, $17.50 \pm 6.69$ versus $17.89 \pm 10.17 \mathrm{pmol} / \mathrm{L}$ at 8 weeks, and $16.35 \pm 5.92$ versus
$18.66 \pm 11.46 \mathrm{pmol} / \mathrm{L}$ at 12 weeks). The cumulative rate of achieving euthyroidism increased with duration of MMI therapy throughout the study in both OD-MMI and DDMMI groups which were not significantly different at all visits $(4.8 \%$ versus $4.3 \%$ at 2 weeks, $28.6 \%$ versus $34.8 \%$ 
TABLE 2: Changes in serum $\mathrm{FT}_{3}$ and $\mathrm{FT}_{4}$ levels during treatment with $15 \mathrm{mg} /$ day OD-MMI and $15 \mathrm{mg} /$ day DD-MMI.

\begin{tabular}{cccccc}
\hline & Week 0 & Week 2 & Week 4 & Week 8 & Week 12 \\
\hline Serum FT3 (pmol/L) & & & & & \\
OD-MMI (21 cases) & $29.24 \pm 14.12$ & $11.07 \pm 3.30$ & $8.61 \pm 3.14$ & $5.71 \pm 2.08$ & $5.53 \pm 2.11$ \\
DD-MMI (23 cases) & $23.96 \pm 13.74$ & $11.60 \pm 4.73$ & $8.24 \pm 3.43$ & $6.16 \pm 4.11$ & $6.59 \pm 5.21$ \\
Serum FT4 (pmol/L) & & & & $17.50 \pm 6.69$ \\
OD-MMI (21 cases) & $68.47 \pm 27.80$ & $34.62 \pm 10.68$ & $26.64 \pm 10.17$ & $16.35 \pm 5.92$ \\
DD-MMI (23 cases) & $56.76 \pm 23.94$ & $35.14 \pm 11.07$ & $26.39 \pm 10.55$ & $17.89 \pm 10.17$ & $18.66 \pm 11.46$ \\
\hline
\end{tabular}

Data are demonstrated as mean \pm standard deviation. $15 \mathrm{mg}$ /day OD-MMI, $15 \mathrm{mg} /$ day of methimazole administered once daily; $15 \mathrm{mg} / \mathrm{day}$ DD-MMI, $15 \mathrm{mg} /$ day of methimazole administered dividedly in $5 \mathrm{mg}$ three times a day. No significant difference in all parameters between the two groups.

TABLE 3: Cumulative rate of achieving euthyroidism and occurrence of hypothyroidism during treatment with $15 \mathrm{mg} / \mathrm{day}$ OD-MMI and $15 \mathrm{mg} /$ day DD-MMI.

\begin{tabular}{|c|c|c|c|c|c|}
\hline & $\begin{array}{c}\text { Week } 0 \\
\text { Cases (\%) }\end{array}$ & $\begin{array}{c}\text { Week } 2 \\
\text { Cases (\%) }\end{array}$ & $\begin{array}{c}\text { Week } 4 \\
\text { Cases }(\%)\end{array}$ & $\begin{array}{c}\text { Week } 8 \\
\text { Cases (\%) }\end{array}$ & $\begin{array}{c}\text { Week } 12 \\
\text { Cases }(\%)\end{array}$ \\
\hline \multicolumn{6}{|l|}{ Euthyroidism } \\
\hline OD-MMI $(n=21)$ & $0(0 \%)$ & $1(4.8 \%)$ & $6(28.6 \%)$ & $15(71.4 \%)$ & $18(85.7 \%)$ \\
\hline DD-MMI $(n=23)$ & $0(0 \%)$ & $1(4.3 \%)$ & $8(34.8 \%)$ & $19(82.6 \%)$ & $20(87.0 \%)$ \\
\hline \multicolumn{6}{|l|}{ Hypothyroidism } \\
\hline OD-MMI $(n=21)$ & $0(0 \%)$ & $0(0 \%)$ & $0(0 \%)$ & $0(0 \%)$ & $0(0 \%)$ \\
\hline DD-MMI $(n=23)$ & 0 & 0 & $3(13.0 \%)$ & $1(4.3 \%)$ & $0(0 \%)$ \\
\hline
\end{tabular}

$15 \mathrm{mg} /$ day OD-MMI, $15 \mathrm{mg} /$ day of methimazole administered once daily; $15 \mathrm{mg} /$ day DD-MMI, $15 \mathrm{mg} /$ day of methimazole administered dividedly in $5 \mathrm{mg}$ three times a day. No significant difference in rate of achieving euthyroidism between the two treatment regimens. $15 \mathrm{mg} / \mathrm{day} \mathrm{DD}-\mathrm{MMI}$ induced hypothyroidism significantly more than $15 \mathrm{mg}$ /day OD-MMI $(p<0.05)$.

at 4 weeks, $71.4 \%$ versus $82.6 \%$ at 8 weeks, and $85.7 \%$ versus $87.0 \%$ at 12 weeks) as shown in Table 3. Hypothyroidism was observed in DD-MMI group in 3 cases (13\%) at 4 weeks and 1 case $(4.3 \%)$ at 8 weeks but none in OD-MMI group. The difference in the rate of hypothyroidism was statistically significant $(p<0.05)$. No adverse effects of MMI including skin rash, fever, and sore throat suggesting agranulocytosis and jaundice were observed in both groups.

\section{Discussion}

The ATA/AACE 2011 and ATA 2016 guidelines have recommended MMI for the first antithyroid drug used in the treatment of nonpregnant patients with Graves' hyperthyroidism $[1,2]$. As MMI has a quite short serum half-life of 6-8 hours after a single dose administration [9], it is conventionally administered in two to three divided doses a day during the initial treatment of hyperthyroidism. Since MMI had been demonstrated to present in thyroid gland for as long as 26 hours after a single dose administration [10-12], a number of studies were conducted to examine the effectiveness of the OD-MMI regimen with and without comparison with the DD-MMI regimen in the treatment of hyperthyroidism using MMI at the daily dosages of 10 to $40 \mathrm{mg}$, and the results showed that the rate of achieving euthyroidism ranged from $32 \%$ to $93 \%$ in 12 weeks which were comparable to that of DD-MMI [5-8, 13-16]. Accordingly, the OD-MMI regimen has been recommended as an alternative to the DD-MMI regimen [1-4] especially in patients with nonsevere thyrotoxicosis [2]. However, it is not clearly stated whether the OD-MMI and DD-MMI regimens are equally effective especially when using MMI at the currently recommended lower daily dosage of $15 \mathrm{mg}$ as the evidences supporting the equal effectiveness of both regimens were based on only few studies that used unequal $[5,6]$ or high daily dosages of MMI [7] or carbimazole [17, 18] in comparison between the OD-MMI and DD-MMI regimens. To our best knowledge, the present study was the first randomized controlled study which aimed to compare the efficacy of OD-MMI with that of DD-MMI regimens by using an equal low daily dosage of $15 \mathrm{mg} /$ day of MMI in the treatment of hyperthyroidism. The reasons for using MMI at the daily dosage of $15 \mathrm{mg}$ in this study were based on the results of previous studies showing that treatment with $15 \mathrm{mg} /$ day of MMI resulted in similar intrathyroidal concentrations of MMI [12], a similar effect on perchlorate discharge test [5], equal efficacy in the reduction of serum thyroid hormones and induction of euthyroidism to treatment with $30 \mathrm{mg}$ /day of MMI $[5,6]$, and comparable results on long-term remission rate [6].

The present study has shown that with the low daily dosage of $15 \mathrm{mg} /$ day of MMI, once daily administration (OD-MMI) is as effective as divided doses administration (DD-MMI) not only in the reduction of serum FT3 and FT4 levels but also in the induction of euthyroidism with the rate of achieving euthyroidism of $85.7 \%$ and $87.0 \%$, respectively, which were similar to those of previous studies [5-8, 14-16]. The equal effectiveness in inducing euthyroidism of low daily dose OD-MMI and DD-MMI regimens 
observed in this study was similar to the results of previous studies that used either high daily dosage or unequal daily dosage of MMI or carbimazole, a prodrug of MMI, in comparison between OD-MMI and DD-MMI regimens. A randomized study in 18 Graves' hyperthyroid patients by Roti et al. using high daily dosage of $40 \mathrm{mg}$ of MMI showed that both single daily and divided doses administration resulted in normalization of serum T3 and T4 levels in all patients by day 30 [7]. A study in 33 hyperthyroid patients by Gupta et al. using high daily dosage of $30 \mathrm{mg}$ of carbimazole showed that both $30 \mathrm{mg}$ once daily (19 cases) and $10 \mathrm{mg}$ three times daily (14 cases) administration resulted in euthyroidism in $100 \%$ in 6 weeks [17]. Another randomized study by Mafauzy et al. using $30 \mathrm{mg} /$ day of carbimazole showed that once daily (17 cases) and divided three times daily (15 cases) administration resulted in euthyroidism or hypothyroidism in $76.5 \%$ and $80.0 \%$, respectively, in 6 weeks [18]. There were two studies in patients with Graves' hyperthyroidism comparing effectiveness of $15 \mathrm{mg}$ once daily regimen with that of $10 \mathrm{mg}$ three times daily regimen showed no significant difference in rate of achieving euthyroidism after 8 weeks (80\% versus $80 \%)$ [6] and 12 weeks (93\% versus $86 \%$ ) [5] of treatment.

The equal effectiveness of the OD-MMI and DD-MMI regimens in the reduction of serum thyroid hormones and induction of euthyroidism either using high daily dosage of MMI as shown in previous studies or low daily dosage of MMI as shown in this study can be explained by results of previous studies on relationships among MMI dosages, intrathyroidal concentrations of MMI [12], and effect of MMI on thyroid hormone synthesis assessed by perchlorate discharge test [5]. Huang et al. showed that intrathyroidal concentrations of MMI increased with increasing dosage of MMI from 5-15 mg/day administered either in single or divided doses and did not further increase with the dosage of MMI above $15 \mathrm{mg} /$ day [12]. Shiroozu et al. showed that a single administration of $15 \mathrm{mg}$ of MMI resulted in a comparable rate of positive perchlorate discharge test and percentages of perchlorate discharge to those resulted from a single administration of $30 \mathrm{mg}$ of MMI in patients with Graves' hyperthyroidism [5].

In the present study, with the low daily dosage of $15 \mathrm{mg}$ of MMI, hypothyroidism was observed in DD-MMI group significantly more than in OD-MMI group (17.4\% versus $0 \%$, $p<0.05)$. Our observation did not agree with that of Mafauzy et al. showing that after a 6-week treatment with high daily dosage of $30 \mathrm{mg}$ of carbimazole, single daily dose administration induced higher rate of hypothyroidism than did the divided daily doses administration (58.8\% versus 29.0\%) [18]. The difference in the incidence of hypothyroidism during antithyroid therapy between ours and Mafauzy's study [18] might be due to the difference in daily dosage of antithyroid drugs used in both studies. The lower rate of hypothyroidism observed in OD-MMI than in DD-MMI using the same daily dosage of MMI could not be clearly explained. The lower mean baseline serum FT3 and FT4 levels in DD-MMI than OD-MMI should not be the explanation as these differences were not statistical significant. Further study in a larger number of patients is needed to verify whether the OD-MMI and DD-MMI regimens induced different rates of hypothyroidism.

Regarding the adverse effects of ATD therapy, a prospective randomized trial of antithyroid drug dose in Graves' disease therapy by the European Multicenter Study Group on Antithyroid Drug Treatment [16] and a systematic review of antithyroid drug regimen for treating Graves' hyperthyroidism by Abraham et al. [19] have shown that treatment with higher daily dosage of an antithyroid drug induced more side effects than treatment with lower daily dosage. Therefore, the absence of minor and major adverse effects of MMI observed in both treatment regimens in this study might be due to the use of low daily dosage of MMI and the quite small sample size.

One reason for recommending OD-MMI rather than DD-MMI regimen for treatment of hyperthyroidism was that OD-MMI regimen might increase patients' compliance in MMI administration that might subsequently improve treatment outcome. Nicholas et al. showed that once daily administration of MMI was as effective as thrice daily administration of propylthiouracil in improving thyroid indices and clinical markers with higher drug compliance (83.3\% versus 53.3\%) [15]. However, in the present study, there was no difference in rate of poor drug compliance between both OD-MMI and DD-MMI regimens. This might be explained by the fact that the patients in both treatment regimens received an intensive instruction about the importance of completely taking methimazole at every visit during the study.

The present study has some limitations. Firstly, the lack of TRAb results in most of our patients might lead to an argument that the cause of hyperthyroidism in some patients may not be Graves' disease. However, the use of clinical specific features including diffuse goiter with bruit, ophthalmopathy, and dermopathy in this study should be acceptable for establishing the diagnosis of Graves' hyperthyroidism according to the ATA/AACE 2011 and ATA 2016 guidelines that TRAb assay and RAIU test may not be necessary in patients who have overt clinical features of Graves' disease $[1,2]$. In addition, other common causes of hyperthyroidism such as toxic adenoma, toxic multinodular goiter, and thyroiditis were excluded by not enrolling patients who had single or multiple palpable thyroid nodules and painful goiter. Secondly, the sample size of this study might be too small to clearly demonstrate the differences in rate of hypothyroidism and other adverse effects induced by OD-MMI and DDMMI regimens. Thirdly, the equal effectiveness of low daily dosage of OD-MMI and DD-MMI regimens in the induction of euthyroidism in patients with clinically nonsevere Graves' hyperthyroidism as shown in this study might not be able to apply for patients with severe Graves' hyperthyroidism.

\section{Conclusions}

Treatment with methimazole at the low daily dosage of $15 \mathrm{mg} /$ day once daily administration is as effective as divided daily doses administration not only in the reduction of serum thyroid hormone levels but also in the induction of euthyroidism. The results of this study support the recommendation 
to administer methimazole, despite at low daily dosage, in single daily dose rather than in divided daily doses in the treatment of clinically nonsevere Graves' hyperthyroidism.

\section{Conflicts of Interest}

The authors declare no conflict or competing interest related to this study.

\section{Acknowledgments}

This study was supported by Siriraj Research Development Fund managed by The Routine to Research (R2R) Project, Faculty of Medicine Siriraj Hospital, Mahidol University. The authors gratefully acknowledge Dr. Akarin Nimmannit for his advice in the statistical methods.

\section{References}

[1] R. S. Bahn, H. B. Burch, D. S. Cooper et al., "Hyperthyroidism and other causes of thyrotoxicosis: management guidelines of the American Thyroid Association and American Association of Clinical Endocrinologists," Endocrine Practice, vol. 17, no. 3, pp. 456-520, 2011.

[2] D. S. Ross, H. B. Burch, D. S. Cooper et al., "2016 American Thyroid Association guidelines for diagnosis and management of hyperthyroidism and other causes of thyrotoxicosis," Thyroid, vol. 26, no. 10, pp. 1343-1421, 2016.

[3] D. S. Cooper, "Treatment of thyrotoxicosis," in Werner \& Ingbar's the Thyroid: A Fundamental and Clinical Text, L. E. Braverman, D. S. Cooper, S. C. Werner and S. H. Ingbar, Eds., pp. 492-516, Wolters Kluwer/Lippincott Williams \& Wilkins Health, Philadelphia, PA, USA, 2013.

[4] T. F. Davies, P. Laurberg, and R. S. Bahn, "Hyperthyroid disorders," in Williams Textbook of Endocrinology, S. Melmed, K. S. Polonsky, P. R. Larsen and H. Kronenberg, Eds., pp. 369-415, Elsevier, Philadelphia, PA, USA, 2016.

[5] A. Shiroozu, K. Okamura, H. Ikenoue et al., "Treatment of hyperthyroidism with a small single daily dose of methimazole," The Journal of Clinical Endocrinology and Metabolism, vol. 63, no. 1, pp. 125-128, 1986.

[6] Y. Mashio, M. Beniko, A. Matsuda et al., "Treatment of hyperthyroidism with a small single daily dose of methimazole: a prospective long-term follow-up study," Endocrine Journal, vol. 44, no. 4, pp. 553-558, 1997.

[7] E. Roti, E. Gardini, R. Minelli, M. Salvi, G. Robuschi, and L. E. Braverman, "Methimazole and serum thyroid hormone concentrations in hyperthyroid patients: effects of single and multiple daily doses," Annals of Internal Medicine, vol. 111, no. 2, pp. 181-182, 1989.

[8] M. Homsanit, S. Sriussadaporn, S. Vannasaeng, T. Peerapatdit, W. Nitiyanant, and A. Vichayanrat, "Efficacy of single daily dosage of methimazole $v s$. propylthiouracil in the induction of euthyroidism," Clinical Endocrinology, vol. 54, no. 3, pp. 385-390, 2001.

[9] D. S. Cooper, H. H. Bode, B. Nath, V. Saxe, F. Maloof, and E. C. Ridgway, "Methimazole pharmacology in man: studies using a newly developed radioimmunoassay for methimazole," The Journal of Clinical Endocrinology \& Metabolism, vol. 58, no. 3, pp. 473-479, 1984.
[10] R. Jansson, P. A. Dahlberg, and B. Lindstrom, "Comparative bioavailability of carbimazole and methimazole," International Journal of Clinical Pharmacology, Therapy, and Toxicology, vol. 21, pp. 505-510, 1983.

[11] D. C. McCruden, T. E. Hilditch, J. M. Connell, A. R. McLellan, J. Robertson, and W. D. Alexander, "Duration of antithyroid action of methimazole estimated with an intravenous perchlorate discharge test," Clinical Endocrinology, vol. 26, no. 1, pp. 33-39, 1987.

[12] G. Huang, "Relation between the dosage of methimazole and its intrathyroidal concentrations," Zhonghua Yi Xue Za Zhi, vol. 71, no. 6, pp. 301-3, 22, 1991, 322.

[13] D. J. Bouma and H. Kammer, "Single daily dose methimazole treatment of hyperthyroidism," Western Journal of Medicine, vol. 132, no. 1, pp. 13-15, 1980.

[14] C. T. He, A. T. Hsieh, D. Pei et al., "Comparison of single daily dose of methimazole and propylthiouracil in the treatment of Graves' hyperthyroidism," Clinical Endocrinology, vol. 60, no. 6, pp. 676-681, 2004.

[15] W. C. Nicholas, R. G. Fischer, R. A. Stevenson, and J. D. Bass, "Single daily dose of methimazole compared to every 8 hours propylthiouracil in the treatment of hyperthyroidism," Southern Medical Journal, vol. 88, no. 9, pp. 973-976, 1995.

[16] D. Reinwein, G. Benker, J. H. Lazarus, and W. D. Alexander, "A prospective randomized trial of antithyroid drug dose in Graves' disease therapy. European Multicenter Study Group on Antithyroid Drug Treatment," The Journal of Clinical Endocrinology and Metabolism, vol. 76, no. 6, pp. 1516-1521, 1993.

[17] S. K. Gupta, A. Mithal, and M. M. Godbole, "Single daily dose of carbimazole in the treatment of hyperthyroidism," National Medical Journal of India, vol. 5, no. 5, pp. 214-216, 1992.

[18] M. Mafauzy, W. B. Wan Mohamad, M. K. Zahary, and B. E. Mustafa, "Comparison of the efficacy of single and multiple regimens of carbimazole in the treatment of thyrotoxicosis," The Medical Journal of Malaysia, vol. 48, no. 1, pp. 71-75, 1993.

[19] P. Abraham, A. Avenell, S. C. McGeoch, L. F. Clark, and J. S. Bevan, "Antithyroid drug regimen for treating Graves' hyperthyroidism," Cochrane Database of Systematic Reviews, no. 1, article CD003420, 2010. 


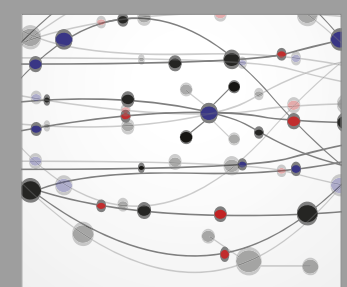

The Scientific World Journal
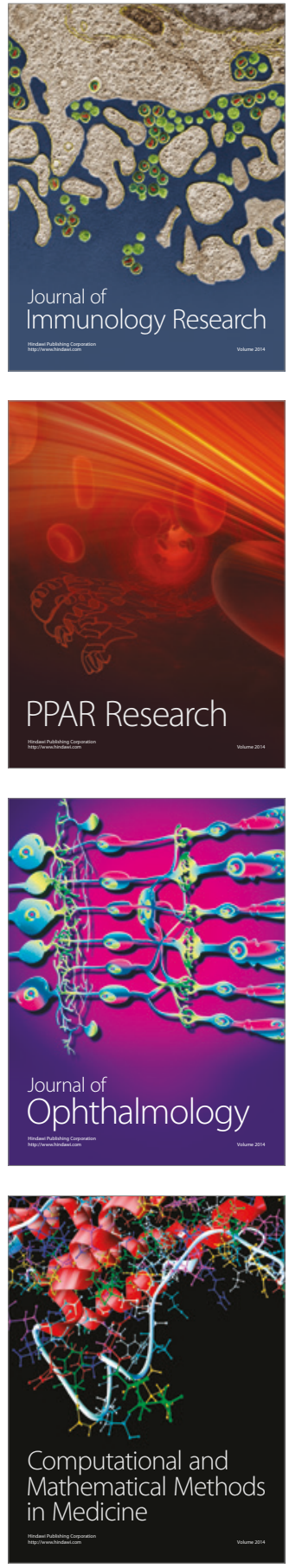

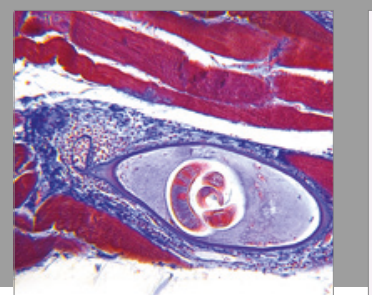

Gastroenterology Research and Practice
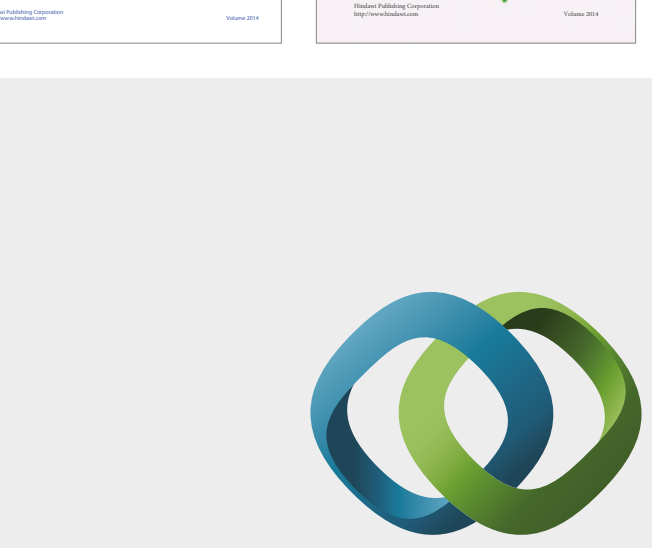

\section{Hindawi}

Submit your manuscripts at

https://www.hindawi.com
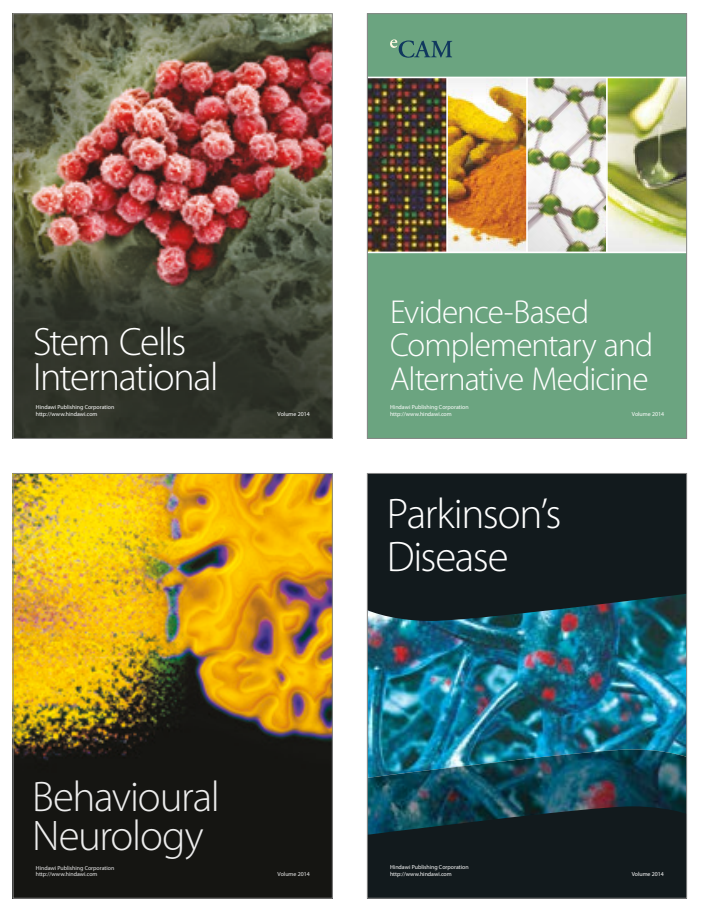
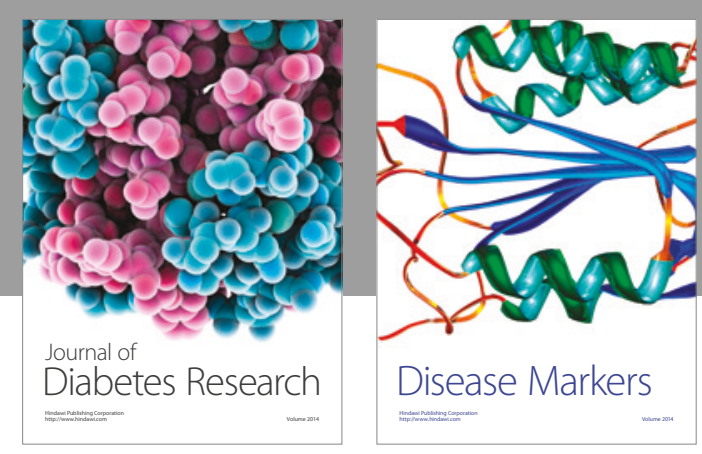

Disease Markers
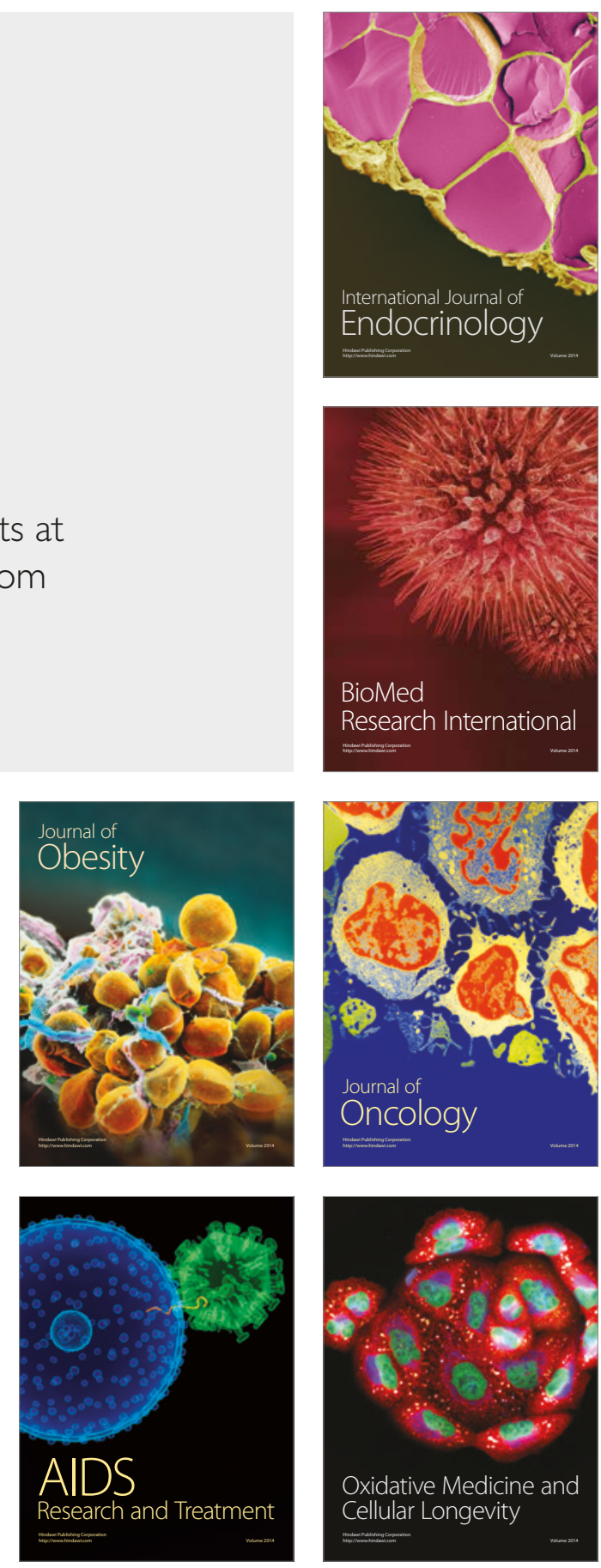